Revista Eletrônica do Mestrado em Educação Ambiental

\title{
Interlocuções da Educação Ambiental, da Abordagem Bioecológica de \\ Desenvolvimento Humano e o conceito de resiliência profissional
}

\author{
Ângela Adriane Schmidt Bersch ${ }^{1}$ \\ Universidade Federal do Rio Grande - FURG \\ ORCID: https://orcid.org/0000-0002-1263-9309 \\ Maria Angela Mattar Yunes ${ }^{2}$ \\ Programa de Pós-Graduação em Psicologia da Universidade Salgado de Oliveira, Niterói, RJ \\ ORCID: https://orcid.org/0000-0002-4653-3895 \\ Narjara Mendes Garcia ${ }^{3}$ \\ Universidade Federal do Rio Grande - FURG \\ ORCID: https://orcid.org/0000-0003-0947-6542
}

Resumo: O artigo apresenta a potência da Abordagem Bioecológica de Desenvolvimento Humano de Urie Bronfenbrenner quando vinculada aos elementos teóricos e práticos da Educação Ambiental. A proposta do olhar ecológico envolve focar os diversos contextos em que a pessoa atua de forma ativa ou passiva e permite construir perspectivas sistêmicas e holísticas das problemáticas humanas e socioambientais. Entre tais questões, esse trabalho destaca as práticas de promoção de resiliência profissional por meio de processos chave e de interconexões dos ambientes

\footnotetext{
${ }^{1}$ Doutora em Educação Ambiental - PPGEA/FURG; Professora Adjunta Instituto de Educação - FURG. Atua nos cursos de graduação em Educação Física e Pedagogia; Coordena projetos de extensão Psicomotricidade Relacional e; Resiliência e formação de Educadores; Coordena o grupo de estudos ECOINFÂNCIAS - infâncias, Ludicidade e Ambientes; participa do Grupo de Estudos GEECAF. e-mail: angelabersch@gmail.com

${ }^{2}$ Graduada em Psicologia pelo Instituto Unificado Paulista (1977), mestrado em Psicologia do Desenvolvimento pela University of Dundee, Escócia (1991) e doutorado em Educação (Psicologia da Educação) pela Pontifícia Universidade Católica de São Paulo (2001). É professora permanente na Universidade Salgado de Oliveira, UNIVERSO, Niterói, RJ e colaboradora no Programa de Pós-Graduação em Educação da Universidade La Salle, CANOAS, RS. e-mail: mamyunes@yahoo.com.br

${ }^{3}$ Pedagoga. Doutora em Educação Ambiental. Professora adjunta no Instituto de Educação da Universidade Federal do Rio Grande - FURG e no Programa de Pós-Graduação em Educação Ambiental (PPGEA). Pesquisadora no Núcleo de Estudo e Pesquisa em Educação da Infância (Nepe/Furg). Líder do Grupo de Pesquisa no CNPq Ecoinfâncias: Infâncias, Ambientes e Linguagens. e-mail: narjaramg@gmail.com
} 
da pessoa em desenvolvimento sob a perspectiva da Educação Ambiental. O objetivo final das reflexões é colaborar para a busca de práticas profissionais, ações e soluções que transformam risco em proteção e resiliência.

Palavras-Chave: Educação Ambiental; Bioecologia do Desenvolvimento Humano; Resiliência.

\title{
Interlocuciones de la educación ambiental, el enfoque bioecológico del desarrollo humano y el concepto de resiliencia professional
}

Resumen: El artículo presenta el poder del Enfoque bioecológico del desarrollo humano de Urie Bronfenbrenner cuando se vincula a los elementos teóricos y prácticos de la Educación Ambiental. La propuesta de la "mirada ecológica" involucra enfocar los diversos contextos en que la persona actúa de forma activa o pasiva y permite una percepción sistémica y holística de las problemáticas socioambientales. Sugiere, también, mirar las capacidades de (re) orientar las prácticas y promover la resistência profesional. Comprender los procesos clave de la resiliencia y lãs interconexiones entre los entornos de la persona em desarrollo desde la perspectiva de la Educación Ambiental. El objetivo último de las reflexiones es colaborar em la búsqueda de prácticas, acciones y soluciones profesionales que transformen el riesgo em protección y resiliencia.

Palabras Clave: Educación Ambiental; Bioecología del Desarrollo Humano; La resiliencia.

\section{Associations among Bioecological Model of Human Development, Environmental}

\section{Education and the concept of professional resilience}

\begin{abstract}
The article presents the strengths of Urie Bronfenbrenner's Bioecological Theory of Human Development when associated to theoretical and practical elements of Environmental Education. The "ecological look" involves focusing on different contexts in which the person is in either with an active or a passive attitude. Italso allows building a systemic and holistic perspective of human and socio-environmental problems. Using the perspectives of Environmental Education, this work high lights the practices of promoting professional resilience through key processes that interconnect the developing person's environments. The lastaim of these reflections is to collaborate searching for professional practices, actions and solutions that transform risk into protection and resilience.
\end{abstract}

keywords: Environmental Education; Bioecology of Human Development; Resilience

\section{Introdução}

O desenvolvimento humano acontece de maneira constante e ampla e pode ser potencializado por interações e relações positivas do indivíduo com ele mesmo, com o outro, com os objetos, símbolos e outros seres, como parte do ambiente. Isso é o que nos propõe a Abordagem Bioecológica do Desenvolvimento Humano, concebida por Urie Bronfenbrenner (1998, 2002 e 2011). Essas relações podem ser determinantes no curso das vidas dos indivíduos em diferentes etapas do desenvolvimento a depender do incentivo ou da inibição de competências, sejam elas na esfera cognitiva, social ou afetiva. Tais 
aspectos têm estreita conexão com as aprendizagens adquiridas nas interações positivas entre o indivíduo, seus pares e demais elementos dos contextos nos quais estão inseridos (MASTEN e GARMEZY, 1985; LUTHAR et al, 2000; YUNES, 2001, RUTTER, 1993, TROMBETA e GUIZZO, 2002).

Resiliência é um fenômeno de desenvolvimento que pode ser potencializado a partir de processos proximais ou relações significativas em diferentes contextos caracterizados por condições de risco. Constata-se resiliência quando são observadas a superação e a transformação do risco por condições de proteção (YUNES, 2015). A resiliência profissional refere-se às possibilidades de a pessoa enfrentar de forma transformadora e ressignificada a exposição a certas circunstâncias, acontecimentos ou fatos adversos que geram condições de risco em seu ambiente de trabalho.

Nesse caso específico de resiliência em contexto profissional, alguns elementos devem ser enfocados como fundamentais no ambiente proximal de trabalho da pessoa: trabalho em equipe, coesão e clareza nas informações do grupo com atenção para a linguagem corporal. Para melhor compreender esses processos chave, o modelo de funcionamento de grupos familiares apresentados por Walsh (2005) é inspirador. São dimensões chave: sistema de crenças, processos de comunicação, e padrões de organização.

Nessa perspectiva sistêmica e processual, também se inserem conceitos da Educação Ambiental (EA) que tratam de uma compreensão integrada do meio ambiente em suas múltiplas e complexas relações, envolvendo aspectos ecológicos, psicológicos, legais, políticos, sociais, econômicos, científicos, culturais e éticos, conforme nos aponta a Lei 9795 em seu art. 5º alínea I (BRASIL, 1999). A Educação Ambiental aposta no equilíbrio dinâmico do ambiente em que a vida é percebida em seu sentido pleno de interdependência dos elementos da natureza (GUIMARÃES, 1995).

Os indivíduos interagem e constroem significados ao longo de sua constituição. Assim, tais ideias estão correlacionadas com a perspectiva teórico-metodológica da Abordagem Bioecológica do Desenvolvimento Humano que possibilita pensar a EA tanto em termos teóricos como práticos. Diante dessa assertiva, surge um importante questionamento inicial: quais as perspectivas teóricas e práticas delineadas sobre a Bioecologia do Desenvolvimento Humano para o campo da Educação Ambiental ${ }^{4}$ ?

No intuito de dar pistas para responder tal questionamento, foi construído um diálogo sobre o "olhar ecológico", ponto chave da Abordagem Bioecológica

\footnotetext{
${ }^{4}$ Este artigo é um recorte da Tese de doutorado da primeira autora orientada pelas demais autoras.
} 
(BRONFENBRENNER, 2002). O olhar ecológico promove a leitura de um contexto proximal e mais imediato, intitulado microssistema, bem como permite perceber nuances e aspectos dos contextos distais que formam o macrossistema. É a construção de uma visão sistêmica, que considera a complexidade e os elementos processuais e temporais da vida em sociedade. Além disso, as características das pessoas e os mecanismos dos processos proximais primários (lugar e símbolos) são considerados motores do desenvolvimento.

Os lugares nos quais os indivíduos estão inseridos (casa, escola, universidade, trabalho etc.) são os microssistemas, onde acontecem as interações mais imediatas e influentes no desenvolvimento. Entretanto, Bronfenbrenner (2002) esclarece que os acontecimentos no macrossistema (valores, políticas públicas, cultura etc.) atingem os microssistemas da pessoa, havendo, portanto, uma interdependência entre todos os contextos.

Assim, um trabalho multidisciplinar numa perspectiva sistêmica é fundamental para abordar questões ambientais e a Abordagem Bioecológica do Desenvolvimento Humano $(\mathrm{ABDH})$ é uma teoria que suscita metodologias potentes para nortear estudos e ações. Portanto, esse artigo visa a relacionar conceitos da Abordagem Bioecológica de Desenvolvimento Humano aos princípios da Educação Ambiental construindo metodologias de estudo do conceito de resiliência em equipes cujas práticas profissionais se situam em contextos de risco.

\section{Abordagem Bioecológica e Educação Ambiental: interlocuções profícuas e potentes}

As articulações da Abordagem Bioecológica de Desenvolvimento Humano $(\mathrm{ABDH})$ com a Educação Ambiental (EA) entre outras coisas, se referem à visão sistêmica sobre reciprocidade nas relações das pessoas e seus múltiplos contextos. A EA propõe a crítica da realidade vivenciada, bem como repensar valores e atitudes com vistas ao equilíbrio local e global como forma de obtenção da melhoria da qualidade de vida (GUIMARÃES, 1995). Fazer esse deslocamento entre o contexto mais imediato da pessoa para o mais distante e observar os acontecimentos, fatos, situações que ocorrem nesses contextos parece ideal para analisar a totalidade.

Conforme o Art. $1^{\circ}$ da LEI no 9.795 entende-se como Educação Ambiental

os processos por meio dos quais o indivíduo e a coletividade constroem valores sociais, conhecimentos, habilidades, atitudes e competências voltadas para a conservação do meio ambiente, bem de uso comum do 
povo, essencial à sadia qualidade de vida e sua sustentabilidade (BRASIL, 1999).

A complexidade e a visão sistêmica da Abordagem Bioecológica de Desenvolvimento Humano estão em considerar os diversos contextos, o tempo e o processo no qual a pessoa está inserida. Esses elementos influenciam o indivíduo que, por sua vez, também exerce influência sobre eles (BRONFENBRENNER, 2011). Tal teia complexa não pode ser dissociada para ser compreendida. Ao dividi-la ou separá-la em partes menores, nos equivocamos facilmente, pois a parte não é igual ao todo e nem o todo igual às partes que dele se originaram (MORIN, 2001).

Bronfenbrenner (2002) esclarece que a pessoa influencia o ambiente, o qual, por sua vez, influencia a pessoa. Essa afirmação é sobremaneira consonante com a área da Educação Ambiental. Nesse sentido, Sauvé (2005) trata da transformação do lugar que se vive, da melhoria da relação de cada pessoa com o mundo a partir da sua bagagem de conhecimento e da contribuição do indivíduo para o desenvolvimento de sociedades responsáveis. Nesse sentido, as relações e interações que ali se estabelecem devem seguir esse mote.

A compreensão do desenvolvimento humano, segundo Bronfenbrenner (1996) também exige o exame de sistemas de interações múltiplas de pessoas e de contextos, e considera aspectos do meio ambiente para além do espaço físico e simbólico mais imediato. Desprezar esse entendimento mais ampliado, complexo e holístico "pode ser caracterizado como estudo do desenvolvimento humano fora do contexto", afirma o autor Bronfenbrenner (1996, p. 18). Importante remarcar o que esse autor entende por ecologia do desenvolvimento humano:

A ecologia do desenvolvimento humano envolve o estudo científico da acomodação progressiva, mútua, entre um ser humano ativo, em desenvolvimento, e as propriedades mutantes dos ambientes imediatos em que a pessoa em desenvolvimento vive, conforme esse processo é afetado pelas relações entre esses ambientes, e pelos contextos mais amplos em que os ambientes estão inseridos. (BRONFENBRENNER, 2002 p. 18)

O autor chama a atenção para alguns aspectos desse conceito: a) a pessoa não é uma tábula rasa ou uma folha em branco que recebe a influência unilateral do ambiente, mas uma pessoa ativa e dinâmica que, ao ingressar num contexto, vai progressivamente reestruturando-o; b) da mesma forma, recebe influência desse contexto num movimento bidirecional, numa interação mútua caracterizada pela reciprocidade; c) essas interações 
não se limitam ao contexto considerado mais imediato, mas inclui as interconexões entre os diversos ambientes com os quais a pessoa tem contato de forma ativa ou passiva (BRONFENBRENNER, 1998). O meio ambiente ecológico concebido por Bronfenbrenner (1998), num exercício de abstração, pode ser considerado como estruturas concêntricas encaixadas umas nas outras, conectadas e articuladas entre si, denominadas de micro, meso, exo emacrossistema.

Quando a criança sai de um microssistema conhecido (como a família) para integrar um novo microssistema (como a escola), há um fenômeno de movimento no espaço ecológico, ou melhor, uma "transição ecológica" (BERSCH e YUNES, 2017). O mesmo ocorre quando o adulto ingressa em um novo contexto de trabalho, universidade ou a chegada de um filho, etc. Conforme Bronfenbrenner, "ocorre uma transição ecológica sempre que a posição da pessoa no meio ambiente ecológico é alterada em resultado de uma mudança de papel, ambiente ou ambos" (BRONFENBRENNER, 2002 p.22). E, este movimento de transição entre um contexto e outro ocorre durante todo o ciclo vital, num sistema de estruturas agrupadas, independentes e dinâmicas. O primeiro nível está relacionado ao efeito de influências proximais, ambientais e orgânicas que advêm do interior do indivíduo, de suas características físicas e de objetos do ambiente imediato, que caracterizam a relação face a face.

O mesossistema envolve inter-relações entre dois ou mais ambientes, nos quais uma pessoa participa ativamente, podendo ser formado ou ampliado sempre que ela passa a fazer parte de novos ambientes. Em alguns casos, por exemplo, esse sistema inclui as relações que uma pessoa mantém em casa, na escola, no clube, com amigos da vizinhança; ou quando tomamos por exemplo os adultos e consideramos as influênciasdos amigos do trabalho, da academia e de outros contextos com os quais tem contato proximal com regularidade.

No exossistema, a pessoa em desenvolvimento não é participante ativa, mas é nesse contexto que podem ocorrer eventos que a afetam ou ainda, podem ser afetados por acontecimentos do ambiente imediato onde a pessoa se encontra. Exossistemas podem ser, para uma criança, o local de trabalho dos pais, a escola do irmão ou a rede de amigos dos pais. Já, para os adultos, podem ser as organizações de bairro, serviço público municipal, postos de saúde, decisões do empregador, etc.

Por fim, para tornar claras as interconexões entre os contextos sistêmicos, o macrossistema envolve todos os outros ambientes sistêmicos formando uma rede ampliada e articulada (ou não) que interage e diferencia uma cultura da outra nos seguintes aspectos: 
religião, os modos de vida, os valores, as ideologias, sistemas de crenças, político, etc. Para exemplificar questões macrossistêmicas, pode-se exemplificar com a estrutura de uma família de classe média da Europa, enquanto sistema grupal, social e cultural que será diferente de um grupo familiar de operários brasileiros.

Os contextos e sistemas acima descritos representam o mapa ecológico do desenvolvimento humano das pessoas.

Vale ressaltar que o autor destaca os processos proximais como interações humanas significativas e motores de desenvolvimento e aprendizagens. As inter-relações são denominadas por Bronfenbrenner (2002) como díades que evoluem de observacionais para primárias. $\mathrm{O}$ autor esclarece: ocorre uma díade "sempre que uma pessoa em um ambiente presta atenção às atividades de uma outra pessoa, ou delas participa, existe uma relação" (BRONFENBRENNER, 2002 p.46). A díade, ele explica, é importante, em especial, por dois aspectos: constitui um contexto crítico para o desenvolvimento e serve como um bloco construtor básico do microssistema que potencializa a formação de estruturas interpessoais maiores - tríades, tétrades e assim por diante (BRONFENBRENNER, 2002).

Tais premissas abordadas na Bioecologia do Desenvolvimento Humano, podem ser associadas ao enfoque sistêmico da Educação Ambiental que aponta para a necessidade de uma educação que desvele a percepção sobre os sistemas complexos e compostos por elementos indissociáveis (biopsicossociais) que compõem o ambiente (SAUVÉ, 2005). Nessa perspectiva, o educador ambiental, tanto no âmbito formal como não formal, pode valer-se desse conhecimento ao propor atividades de estudo ou de intervenção aos seus colaboradores. A compreensão e associação de conceitosda ABDH e da EA é fundamental para refletir e agir sobre os problemas socioambientais, pois nos auxiliam no entendimento de estruturas inter-relacionadas e deconflitos relacionados diretamente com o mapa ecológico de cada um.

Assim, o olhar ecológico que considera o todo e as interconexões dessa totalidade pode promover ações em direção à minimização e resolução de problemas socioambientais, com o objetivo de formar e transformar seres humanos mais humanos (BRONFENBRENNER, 2011). Esse olhar é construído nas relações, compreensão que corresponde ao explicitado por Leff (2011): o saber ambiental se forja no encontro (enfrentamento, entrecruzamento, hibridização, antagonismo) de saberes diferenciados por matrizes de racionalidade-identidade-sentido que respondem a estratégias de poder pela apropriação do mundo e da natureza" (p.331). 
A teoria, nesse sentido, pode contribuir de forma significativa, uma vez que possibilita o olhar ecológico - o qual estará atento aos contextos onde o indivíduo está inserido, a fim de compreender o seu percurso de vida e como tais contextos se relacionam e interferem na vida desse sujeito. A compreensão do desenvolvimento humano, explica Bronfenbrenner (2002), exige o exame de sistemas de interações múltiplas de pessoas e de contextos, considerando aspectos do meio ambiente além do mais imediato. $\mathrm{O}$ desprezo desse entendimento mais ampliado e complexo pode ser caracterizado como um estudo do desenvolvimento humano fora do contexto, gerando uma compreensão equivocada da realidade individual e coletiva.

Nessa ótica e na proficuidade de articular a Bioecologia do Desenvolvimento Humano com a Educação Ambiental, a partir dos estudos de Sauvé (2005) e Leff (2011), enfatizamos a relevância de as ações buscarem a melhoria da qualidade das intra e interrelações. Considerando para tal as experiências, as vivências, o conhecimento de mundo de cada pessoa e sua influência no coletivo e dessa reciprocidade, ou seja, do impacto desse coletivo sobre cada um dos indivíduos que o compõe.

\section{Resiliência profissional sob o escopo da interface da abordagem bioecológica e educação ambiental: reflexões teóricas e implicações práticas}

Segundo a teoria de Bronfenbrenner (2002), os indivíduos são diretamente influenciados pelo modo como percebem e se relacionam no ambiente ao seu redor, bem como os lugares são influenciados e modificados pelos indivíduos numa relação de reciprocidade. A teoria Bioecológica possibilita o olhar ecológico, o qual estará voltado para os contextos onde os indivíduos estão inseridos, a fim de compreender o seu percurso de vida e como esses contextos se relacionam e interferem na vida desse sujeito. $\mathrm{O}$ microssistema é o ambiente mais próximo dos indivíduos, onde acontecem as relações face a face. Assim o define Bronfenbrenner (2002):

microssistema é um padrão de atividades, papéis e relações interpessoais experienciadas pela pessoa em desenvolvimento nos contextos (...), contendo outras pessoas com distintas características de temperamento, personalidade e sistema de crenças (BRONFENBRENNER, 2002, p. 176).

No que diz respeito a tais questões que se referem aos aspectos biopsicossociais e ambientais, Walsh (2005), eminente estudiosa da resiliência, também afirma serem 
inerentes à resiliência no âmbito familiar e os denomina processos chave: Padrões de organização; Sistemas de crenças e valores; Processos de comunicação. Tais fatores possibilitam o indivíduo a lutar e enfrentar os obstáculos, bem como a seguir a vida com mais amor e afeto. Contudo, é prioritário que mecanismos de mediação auxiliem para

superar as vulnerabilidades. A autora afirma que todo indivíduo tem a capacidade/possibilidade de desenvolver resiliência ao longo da vida. No entanto, a resiliência poderá ser potencializada se esse indivíduo contar com outras pessoas - família, amigos, professores, educadores, etc. - que a estimulem, por meio de vínculos afetivos e relações promotoras de desenvolvimento (WALSH, 2005), o que enfatiza o elemento relacional do conceito (YUNES, 2015). Explicaremos os aspectos essenciais desses processos chave para estabelecer as relações com os protagonistas, os educadores sociais do contexto não formal, cenário das nossas investigações.

\section{a. Padrões de organização (Flexibilidade e estabilidade; conexão; recursos sociais e econômicos)}

Atualmente, as famílias organizam-se de diferentes formas para enfrentar os desafios que as assolam. Na organização familiar, a resiliência se sustenta em uma estrutura flexível, com conexões entre os membros e com recursos econômicos e sociais. Em uma situação de divórcio ou um novo casamento, por exemplo, as famílias se veem obrigadas a elaborar outras formas de organização. É preciso, em casos assim, avaliar a situação, calibrar as relações e reorganizar modelos de interação para adaptar-se a nova situação (WALSH, 2005).

Enfrentar uma crise pode significar o rompimento da coesão familiar se os membros dessa família não souberem relacionar-se entre si. Quando a criança passa por uma situação de perda (da mãe, do pai ou de um cuidador primário), é importante que ela sinta e saiba que ainda terá alguém que a cuide e que dela goste.

Nesse sentido, Walsh (2005) cita uma situação em que a menina perde a mãe em um acidente automobilístico e o pai precisa se afastar por duas semanas, por conta do trabalho, deixando-a na casa das tias. O pai percebe que sua filha sofre com a separação e deixa com ela seu relógio, avisando que o tique-taque representa as batidas de seu coração, pois este a ama. Então, ela entrega ao pai um de seus brinquedos favoritos, construindo, assim, um elo de ligação simbólico. Bronfenbrenner (2002) explica que essa forma de organização e esses elementos podem significar componentes construtores de relação e de 
desenvolvimento num processo de transição ecológica. Mesmo o pai estando longe simbolicamente para a criança, ele continua próximo e latente com o tique-taque do relógio.

Exemplos como esse podem ser extremamente válidos para as crianças e os adolescentes que são obrigados a estar nas instituições de acolhimento sem a presença física dos pais ou de seus responsáveis. Com isso, se quer dizer que a mesma lógica de padrões de organização como fortalecedores de resiliência (e que vale para a instituição família) pode ser usada quando se busca analisar, identificar e implementar resiliência em ambientes institucionais. Os educadores sociais devem ter clara a importância da coesão no grupo, no intuito de buscar objetivos em comum. A coesão de equipe no trabalho coletivo que visa à resiliência profissional carece de buscar soluções que sejam comuns a todos. Um profissional, por exemplo, ao enfrentar um problema, pode se inspirar na experiência exitosa do outro colega.

\section{b. Sistema de crenças e valores (dar sentido para adversidade, transcendência e espiritualidade, olhar positivo)}

Outro processo chave defendido por Walsh (2005) é o sistema de crenças familiares que, conforme a autora, influi de maneira significativa na forma como encaramos uma crise, no sofrimento e nas escolhas. As construções de realidade emergem das interações familiares e sociais. Tais edificações entre os membros da família podem significar uma potencialidade ante uma situação de crise, graças à união entre as pessoas. Pode ocorrer, também, o contrário: uma maior fragilidade, caso haja um rompimento das relações familiares devido ao estresse dos acontecimentos. Ainda se percebe um fortalecimento entre os vínculos quando a união se estabelece no enfrentamento das adversidades, podendo, inclusive, prospectar-se para outras gerações (WALSH, 2005).

A família que tem um bom funcionamento, explica Walsh (2005), tem fortes valores de pertencimento. Este é um elemento fundamental para potencializar a resiliência, visto que enfrentar a adversidade como um desafio compartilhado por membros da família constitui uma espécie de fortaleza, na qual o forte é aquele que está junto aos outros, não isolado. O bom funcionamento das relações familiares depende de um sentido evolucionista do tempo e das adversidades, enfrentando um contínuo processo de crescimento e mudanças ao longo da vida e das gerações. (WALSH, 2005). 
Grupos familiares encaram melhor as adversidades se enxergarem sentido, coerência, possibilidade e se é válido superar tal situação. Nessa perspectiva, uma visão positiva diante da vida facilita o enfrentamento de qualquer circunstância. Almejar um futuro melhor, por mais difícil e cruel que seja o presente, é um passo fundamental para o enfrentamento e superação da crise. As famílias com melhor funcionamento têm uma visão mais otimista da vida (WALSH, 2005). Pode-se depreender que isso também ocorrerá com grupos de profissionais em situação de crise, no que tange ao funcionamento operacional.

Enfrentar conflitos e situações adversas com positividade é um mecanismo essencial para a promoção da resiliência profissional. $O$ medo, a insegurança, a desesperança são aspectos que paralisam as pessoas. O grupo, no ambiente institucional, deve olhar para o passado e buscar referências nos momentos e situações difíceis, mas que foram superadas.

Podemos aprender ou desaprender a ser otimistas? Walsh (2005) explica que as primeiras investigações de Martin Seligman ${ }^{5}$ sobre o "desamparo aprendido" mostravam que, com repetidas experiências de fracasso, as pessoas desistiam de tentar e passavam a ser passivas e pessimistas, acreditando que as coisas ruins sempre aconteceriam com elas e que qualquer coisa que fizessem seria inútil. Seligman concluiu que o otimismo poderia ser aprendido e o pessimismo desaprendido por meio de experiências exitosas, construindo relações de confiança e fazendo a pessoa acreditar que seu esforço, mesmo que individual, faria a diferença. Contudo, para qualquer experiência ter êxito e ser sustentável, uma visão positiva deve nutrir-se com experiências exitosas e com um contexto comunitário que promova apoio.

c) Processos de comunicação (Mensagens claras e consistentes; compartilhar emoções, interações positivas e humor; prevenção e resolução colaborativa de problemas)

Os processos de comunicação potencializam a resiliência porque favorecem claridade e transparência às situações de crise, estimulando a expressão emocional e impulsionando a resolução de problemas, uma vez que há colaboração entre os membros da família. Entretanto, é preciso lembrar que as normas culturais diferem consideravelmente quando as pessoas compartilham a expressão de seus sentimentos e as informações que os afetam. A claridade e congruência na comunicação ao emitir uma

\footnotetext{
${ }^{5}$ Psicólogo americano, professor da Universidade da Pensilvânia e ex-presidente da Associação Americana de Psicologia. Ele é conhecido mundialmente como criador da psicologia positiva.
} 
mensagem facilitam o funcionamento eficaz da família. Ter momentos de diálogos e falar sobre situações difíceis podem amenizar desentendimentos e/ou entendimentos ambíguos (WALSH, 2005) em qualquer situação de dificuldade.

Nessa lógica de pensamento, é possível levar essa mesma reflexão para o âmbito das instituições de acolhimento, cenário de nossa investigação, que lidam quase diariamente com informações dolorosas, seja com relação ao comportamento de alguma criança/adolescente institucionalizado, seja com relação a sua família. Enfim, o contexto das instituições de abrigo é minado de Geisers, que são como notícias dolorosas que podem entrar em erupção a qualquer momento, sem que se saiba previamente a intensidade, volume ou extensão que irá atingir. Assim, uma mesma informação pode afetar os envolvidos de diversas formas, pois cada um deles tem recursos mentais singulares para lidar com tal informação. Apesar disso, essa singularidade poderia ser minimizada se houvesse comunicação e canais de diálogos entre os pares (BERSCH et al, 2019).

Construir canais coesos de comunicação, momentos e espaços de diálogos entre os educadores sociais devem ser estratégias para amenizar os conflitos relacionais no contexto. A elaboração de táticas em conjunto para as adversidades e o trabalho em prol dos mesmos objetivos podem significar a superação de dois aspectos presentes nas instituições e que são pauta de discussão entre os profissionais que ali atuam: conflitos nas relações entre os profissionais e institucionalizados; desconhecimento da organização institucional.

Mobilizar os Educadores Sociais para esses momentos e espaços de forma permanente pode ser uma alavanca na resiliência do contexto profissional. Isso porque há a oportunidade de se provocar discussões e reflexões sobre as carências e demandas, envolvendo um clima agradável, de confiança, de positividade, com humor positivo, movimento, disponibilidade corporal e olhar prospectivo. "Encontrar pracer y momentos de humor en médio del dolor puede dar um respiro y levantar el ánimo" (WALSH, 2005 p.16).

Walsh (2005) alega que à medida que as famílias esclarecem, explicam as informações e expressam seus sentimentos de forma clara e sincera, os membros do grupo familiar fortalecem as atitudes e dão mais sentido a situações e suas posições ante os problemas. Dessa maneira, fazem renascer a esperança e facilitam a resolução efetiva de problemas. Assim, as famílias ampliam seus recursos, reduzem o risco de vulnerabilidade e têm melhores condições para enfrentar desafios que possivelmente virão. A autora ainda 
conclui que "asípues, construir la resilencia también es uma medida preventiva" (WALSH, 2005 p.17).

Ao tratar dos processos chaves, Walsh (2005) se refere aos mecanismos de proteção que mobilizam a pessoa a superar, com positividade, as adversidades. A criança ou o adolescente muitas vezes não querem estar na instituição de acolhimento. No entanto, sentem-se na obrigação de estar em um local desconhecido e com estranhos (PISKE et al, 2017). É importante que ela perceba, dentro desse novo contexto, relações de afeto, especialmente com algum dos profissionais. Esse fato pode representar um fator de proteção e promotor de resiliência para os envolvidos. Manter uma comunicação permanente, afetuosa, clara e com interpretação unívoca de informações pode ser um dos elementos para ampliar a potência e energizar a capacidade de resiliência no contex to profissional dos Educadores Sociais.

A Abordagem Bioecológica possibilita uma percepção mais acurada do microssistema instituição de acolhimento, âmbito em que desenvolvemos uma pesquisa empírica que teve como objetivo, por meio de um Programa de Formação para os Educadores Sociais, promover a resiliência profissional (BERSCH et al, 2019). Segundo estudos de Yunes, Miranda, Cuello (2004), realizados no município de Rio Grande, podese constatar que o ambiente institucional e as relações estabelecidas neste meio (pela criança e pelo adolescente) podem apresentar tanto ou mais riscos ao desenvolvimento cognitivo, social e afetivo quanto à permanência na família da qual a pessoa em desenvolvimento foi retirada, podendo comprometer a construção de sua identidade e projetos futuros.

A proposta de um Programa de Formação continuada para os Educadores Sociais, que atende crianças e adolescentes institucionalizados, tem por objetivo promover a resiliência no contexto profissional, sob a perspectiva da Educação Ambiental não formal. Esta última tem como finalidade trabalhar em prol da melhoria do atendimento dos Educadores Sociais para potencializar uma melhor qualidade de vida destes e dos residentes.

Acredita-se que isso somente será possível por meio da práxis, o processo de ação/reflexão (FREIRE, 1996) em que teremos, como resultado, uma nova ação por meio da transformação dos sujeitos envolvidos e por consequência do microssistema. Bronfenbrenner (2002) afirma que, se queremos mudar ambientes, precisamos mudar os comportamentos. Este é, então, o foco da pesquisa: mudar o ambiente de acolhimento para um ambiente potente, em termos desenvolvimento, por meio de mudanças significativas no 
comportamento dos Educadores Sociais e nas suas relações com as crianças e adolescentes acolhidos.

E para que tal conquista seja efetivamente celebrada, é imprescindível investigar a atuação dos profissionais que atendem às crianças e aos adolescentes e que têm, ou deveriam ter, um papel fundamental. São esses cuidadores que podem representar o esteio num momento de solidão, dor, sofrimento e angústia em que se encontram os acolhidos. Além disso, são eles que podem ser os "propulsores" de desenvolvimento saudável para essa população em situação de risco psicossocial. No entanto, como num mundo vulnerável, incerto e inconstante, no qual é cada vez mais difícil conduzir a própria vida com iniciativa, maturidade e segurança, como viver a responsabilidade de guiar outras pessoas no processo de construção da sua própria autonomia? Será que esse Educador Social se percebe como um sujeito de transformação ou um tutor de transformações?

Por isso, a formação contínua é imprescindível. Obviamente que tal tarefa não é simples: ela é extremamente complexa. Implica em orientar o grupo respeitando as diversidades de ideias, crenças e valores, no intuito de canalizá-las para objetivos comuns dos envolvidos, para propostas educativas protetivas. Ter o foco na promoção da resiliência no contexto profissional e garantir que o Educador Social seja um tutor de resiliência talvez tenham sido os maiores desafios da proposta do referido Programa, tendo em vista que as imagens sociais negativas e pessimistas sobre esse lugar - instituição de acolhimento - são históricas e culturais (BERSCH e YUNES, 2015; 2017; BERSCH et al, 2019).

Num Programa de Formação, nesse emaranhado de relações entre sujeitos e lugares, o indivíduo (no caso, o Educador Social) deve tomar consciência de si mesmo, de seu papel na sociedade, de seus afetos, de suas relações consigo mesmo, bem como com o outro, de seus valores, de suas crenças, que são princípios constituintes da Educação Ambiental. Esses aspectos também coadunam com os processos chave da resiliência: padrões de comunicação, sistemas de organização e sistemas de crenças (WALSH, 2005). Para um melhor entendimento da resiliência em contexto profissional, é preciso entender as características individuais e, especialmente, voltar o olhar para os processos coletivos.

Tal compreensão, atrelada aos estudos, ações e intenções da EA, nos parece fecunda, visto que a ABDH propõe uma visão sistêmica dos contextos e suas inter-relações - fato que é extremamente profícuo se quisermos trabalhar com o conhecimento mais claro e profundo das problemáticas ambientais, principalmente a respeito de suas causas, e não somente voltar o olhar para as preocupações e ações sobre as consequências. 


\section{Considerações Finais}

A Educação Ambiental visa melhor qualidade de vida do indivíduo e da coletividade por meio da crítica da realidade vivenciada pela pessoa em desenvolvimento, o que implica em refletir e repensar valores, condutas, posturas e atitudes. O olhar ecológico do educador ambiental promove a percepção de que as emoções e relações devem ser valorizadas, e que a resiliência é potencializadora de desenvolvimento e de saúde. Além disso, propicia a integração dos indivíduos, possibilitando-lhes uma maior segurança nas suas decisões, juntamente com a promoção da resiliência no contexto profissional.

Considerar o mapa ecológico da pessoa e dos ambientes poderá contribuir para uma compreensão mais sistêmica das problemáticas e ações no sentido de prevenção, além de amenizar comportamentos nocivos, individualistas e opressores. Acreditamos que a teoria pode contribuir significativamente para o campo da Educação Ambiental, em especial na perspectiva sistêmica, pois compreender o desenvolvimento humano é compreender como os seres humanos convivem em sociedade e como seres que habitam a Terra, que estão sistemicamente interligados com outros humanos e não humanos.

As interfaces entre a Educação Ambiental, a Bioecologia do Desenvolvimento Humano e a Resiliência profissional são possibilidades concretas de subsidiar ações, intervenções e projetos na superação de histórias e cenários fragilizados, em que indivíduos se mostram vulneráveis e em situação de risco social e pessoal. A interlocução entre essas teorias poderá inspirar e subsidiar Programas de Formação contínua e permanente de Agentes e Educadores Sociais que trabalham em condições adversas. e precisam de mecanismos de proteção no seu cotidiano. Tais estratégias positivas podem gerar processos de resiliência profissional para as equipes.

Um Programa deve visualizar as diversas complexidades e potencialidades do contexto por meio do olhar ecológico. Considerar o microssistema e seus atores, objetos, símbolos e relações são oponto de partida das análises. Deve-se considerar ainda, o meso, exo e o macrossistema como interdependentes deste micro, o que é vital para articulação com a EA. Tal área tem, entre seus objetivos, a compreensão integrada do meio ambiente e sua multiplicidade e complexidade nas relações, que abarcam não só os aspectos eco e psicológicos, mas, também (e com a mesma força), os aspectos legais, políticos, sociais, éticos, econômicos, científicos e culturais. Este entremear de campos de conhecimento 
possibilitam potencializar e promover resiliência em contexto profissional e de situações de risco.

O Educador Social nessa proposta assume papeis essenciais, por exemplo, no contexto das instituições de acolhimento: o de Educador Ambiental e de Educador Social. Enquanto ator social, explicam Carvalho e Baptista (2004), papel comum a todos os seres humanos, ele convive com a complexidade da vida em sociedade. Entretanto, ao incorporar o papel de educador ambiental, ele deve ser sujeito de um processo de sensibilização e problematização da realidade. A amalgama desses papéis potencializa a consolidação e renovação de redes que já existem no contexto. Além disso, auxilia na promoção de novas conexões, novas possibilidades, espaços de pertencimento e de referências afetivas, aspectos intimamente relacionados com a Bioecologia e com a Educação Ambiental, que tonificam sobremaneira a resiliência profissional.

\section{Referências}

BERSCH, Ângela Adriane Schmidt. Resiliência profisssional e a Educação Ambiental: promoção de ambientes de desenvolvimento em instituição de acolhimento. Tese (doutorado) - Universidade Federal do Rio Grande - FURG, Programa de Pós-graduação em Educação Ambiental, Rio Grande/RS, 193 f. 2017.

BERSCH, Ângela Adriane Schmidt.; YUNES, Maria Angela Mattar. O brincar na pediatria hospitalar: análise bioecológica da saúde ambiental. Verlag: Novas edições acadêmicas, 2017.

BERSCH, Ângela Adriane Schmidt.; YUNES, Maria Angela Mattar.; GARCIA, Narjara Mendes. Educação social e educação ambiental: a (re)significação da identidade do educador social. In: XV Encontro Paranaense de Educação Ambiental (EPEA), Guarapuava. Anais XV Encontro Paranaense de Educação Ambiental (EPEA), Guarapuava, PR: UNICENTRO, 2015a.

BERSCH, Ângela Adriane Schmidt; PISKE, Eliane Lima; YUNES, Maria Angela Mattar; GARCIA, Narjara Mendes; SILVEIRA, Simone Biazzi Ávila; PIETRO, Ângela Torma. Programa de formação de educadores sociais na promoção da resiliência profissional. Rio Grande: Ed. da FURG, 2019. Disponível em: http://repositorio.furg.br/bitstream/handle/1/7867/EbookCompleto.pdf?sequence=3

BRASIL. Programa nacional de educação ambiental - ProNEA / Ministério do Meio Ambiente, Diretoria de Educação Ambiental; Ministério da Educação. Coordenação Geral de Educação Ambiental. - 3. ed - Brasília : Ministério do Meio Ambiente, 102 p, 2005.http://www.mma.gov.br/estruturas/educamb/_arquivos/pronea3.pdf 
BRASIL. Lei n. 9795 - 27 de abril de 1999. Dispõe sobre a educação ambiental. Política Nacional de Educação Ambiental. Brasília, 1999.http://www.planalto.gov.br/CCIVil_03/LEIS/L9795.htm

BRONFENBRENNER, Urie; MORRIS,Pamela. The ecology of developmental processes. In: W. DAMON (org.), Handbook of child psychology. New York, NY: John Wiley $\begin{array}{lllll}\text { \&Sons, } & \text { v.1, } & \text { p. } & 993-1027, & 1998 .\end{array}$ http://www.scielo.br/scielo.php?script=sci_nlinks\&ref=000078\&pid=S0102$\underline{7972200300030001000007 \& \operatorname{lng}=\text { en }}$

BRONFENBRENNER, Urie. A ecologia do desenvolvimento humano: experimentos naturais e planejados. Porto Alegre: Artes Médicas, 2002

BRONFENBRENNER, Urie. Bioecologia do desenvolvimento humano: tornando os seres humanos mais humanos. Tradução André de Carvalho-Barreto. Porto Alegre: Artmed, 2011

CARVALHO, Adalberto D.; BAPTISTA, Isabel. Educação Social :Fundamentos e estratégias. Porto: Porto Editora, 2004.

FREIRE, Paulo. Pedagogia da autonomia: saberes necessários à prática educativa. São Paulo: Paz e Terra, 1996.

GUIMARÃES, Mauro.A dimensão ambiental na educação. Campinas: Papirus. Coleção Magistério: Formação e Trabalho Pedagógico, 1995.

LEFF, Enrique. Complexidade, interdisciplinaridade e saber ambiental. Olhar de professor,Ponta Grossa, v. 14, n. 2, p. 309-335, 2011. Disponível em http://www.revistas2.uepg.br/index.php/olhardeprofessor

LUTHAR, SunyaS., CICCHETTI, Dante; BECKER, Bronwyn. The construct of resilience: a critical evaluation and guidelines for future work. Child Development, v. 71, n.3, p. 543562 ,

2000.https://www.researchgate.net/publication/12366925_The_Construct_of_Resilience A_Critical_Evaluation_and_Guidelines_for_Future_Work

MASTEN, Ann.S.; GARMEZY, Norman. Risk, vulnerability and protective factors in developmental psychopathology. In: LAHEY, B. (Org.), Advances in clinical child psychology. New York: Plenum Press, n.8, p.1- 52, 1985.

MORIN, Edgar. Os sete saberes necessários à educação do futuro. São Paulo. Cortez; Brasilia, DF:UNESCO, 2001.

PISKE, Eliane Lima; BERSCH, Angela Adriane Schmidt;YUNES, Maria Angela Mattar. Children's perceptions of the relational and educational practices at shelter institutions. In D. D. Dell'Aglio; S. H. Koller (Eds.), Vulnerable children and youth in Brazil: Innovative approaches from the psychology of social development, p. 191-210, 2017. Springer International Publishing. https://doi.org/10.1007/978-3-319-65033-3_13 
RUTTER, Michael. Resilience: some conceptual considerations. Journal of adolescent health, v.14, p. 626-631, 1993.https://www.jahonline.org/article/1054-139X(93)90196$\underline{\text { V/fulltext }}$

SAN MARTÍN, Daniel Cantero. Teoría fundamentada y Atlas.ti: recursos metodológicos para la investigación educativa. Revista Electrónica de Investigación Educativa, v.16, n.1, p. 104-122. 2014. Recuperado em 20 de abril, 2016, de http://www.scielo.org.mx/pdf/redie/v16n1/v16n1a8.pdf

SAUVÉ, Lúcia. Educação Ambiental: possibilidades e limitações. Educação e Pesquisa, São Paulo, v. 31, n. 2, p. 317-322, maio/ago., 2005.http://www.scielo.br/scielo.php?script=sci_arttext\&pid=S1517$97022005000200012 \& \operatorname{lng}=\mathrm{pt} \& \operatorname{tlng}=\mathrm{pt}$

STAUSS, Anselm; CORBIN, Juliet. Bases de la investigación cualitativa. Técnicas y procedimientos para desarrollar la teoría fundamentada. Editorial Universidad de Antioquia. Medellin (Colombia). 2012

SZYMANSKI, Heloísa.; YUNES, Maria Angela Mattar. Entrevista Reflexiva \&GroundedTheory:Estratégias Metodológicas para Compreensão da Resiliência em Famílias. Revista Interamericana de Psicología/InteramericanJournalofPsychology. v.39, n. 3, 2005. http://www.redalyc.org/pdf/284/28439313.pdf

TROMBETA, Luisa Helena Albertini.; GUZZO, Raquel Souza Lobo. Enfrentando o cotidiano adverso: estudo sobre resiliência em adolescentes. Campinas: Alínea, 2002.

WALSH, Froma. Resiliencia Familiar: um marco de trabajo para La práctica clínica. $\begin{array}{lllll}\text { Sistemas } & \text { Familiares, } & \text { Buenos } & \text { Aires, } 1-25, & \end{array}$ http://www.redalyc.org/pdf/264/26416966005.pdf

YUNES, Maria Angela Mattar; SZYMANSKI, Heloisa. Resiliência: noção, conceitos afins e considerações críticas. In: TAVARES José (Org.) Resiliência e Educação. São Paulo: Cortez, 2001.

YUNES, Maria Angela Mattar; MIRANDA, Angela Torma; CUELLO, Sandra Eliane Sena. Um olhar ecológico para os riscos e as oportunidades de desenvolvimento de crianças e adolescentes institucionalizados. In: KOLLER, Silvia H. (Org.). Ecologia do desenvolvimento humano: pesquisa e intervenção no Brasil. São Paulo: Casa do Psicólogo, p. 197-218, 2004.

YUNES, Maria Angela Mattar. Dimensões conceituais da resiliência e suas interfaces com risco e proteção. In: MURTA, SheilaG.; FRANÇA, CristineideL.; BRITO, Karine; POLEJACK, Larissa (Org.). Prevenção e Promoção em Saúde Mental: Fundamentos, Planejamento e Estratégias de Intervenção. $1^{a}$ ed.Novo Hamburgo: Synopisis, p. 93-112, 2015. 
Submetido em: 27-03-2020.

Publicado em: 18-12-2020. 